\title{
DNA methylation regulates expression of VEGF-R2 (KDR) and VEGF-R3 (FLT4)
}

\author{
Hilmar Quentmeier ${ }^{1 *}$, Sonja Eberth ${ }^{1,2}$, Julia Romani ${ }^{1}$, Herbert A Weich ${ }^{3}$, Margarete Zaborski ${ }^{1}$ and Hans G Drexler ${ }^{1}$
}

\begin{abstract}
Background: Vascular Endothelial Growth Factors (VEGFs) and their receptors (VEGF-Rs) are important regulators for angiogenesis and lymphangiogenesis. VEGFs and VEGF-Rs are not only expressed on endothelial cells but also on various subtypes of solid tumors and leukemias contributing to the growth of the malignant cells. This study was performed to examine whether VEGF-R2 (KDR) and VEGF-R3 (FLT4) are regulated by DNA methylation.

Methods: Real-time (RT) PCR analysis was performed to quantify KDR and FLT4 expression in some ninety leukemia/lymphoma cell lines, human umbilical vein endothelial cells (HUVECs) and dermal microvascular endothelial cells (HDMECs). Western blot analyses and flow cytometric analyses confirmed results at the protein level. After bisulfite conversion of DNA we determined the methylation status of KDR and FLT4 by DNA sequencing and by methylation specific PCR (MSP). Western blot analyses were performed to examine the effect of VEGF-C on p42/44 MAPK activation.

Results: Expression of KDR and FLT4 was observed in cell lines from various leukemic entities, but not in lymphoma cell lines: 16\% (10/62) of the leukemia cell lines expressed KDR, 42\% (27/65) were FLT4 positive. None of thirty cell lines representing six lymphoma subtypes showed more than marginal expression of KDR or FLT4. Western blot analyses confirmed KDR and FLT4 protein expression in HDMECs, HUVECs and in cell lines with high VEGF-R mRNA levels. Mature VEGF-C induced p42/44 MAPK activation in the KDR /FLT4 ${ }^{+}$cell line OCI-AML1 verifying the model character of this cell line for VEGF-C signal transduction studies. Bisulfite sequencing and MSP revealed that GpG islands in the promoter regions of KDR and FLT4 were unmethylated in HUVECs, HDMECs and $K D R^{+}$and $F L T 4^{+}$cell lines, whereas methylated cell lines did not express these genes. In hypermethylated cell lines, $K D R$ and FLT4 were re-inducible by treatment with the DNA demethylating agent 5-Aza-2'deoxycytidine, confirming epigenetic regulation of both genes.
\end{abstract}

Conclusions: Our data show that VEGF-Rs KDR and FLT4 are silenced by DNA methylation. However, if the promoters are unmethylated, other factors (e.g. transactivation factors) determine the extent of KDR and FLT4 expression.

\section{Background}

Vascular endothelial growth factors (VEGFs) and their corresponding receptors (VEGF-Rs) are important regulators of angiogenesis and lymphangiogensis. VEGF-A binds VEGF-R1 (FLT1) and VEGF-R2 (KDR). Both tyrosine kinase receptors are expressed on blood vessel endothelial cells. VEGF-C and VEGF-D bind to VEGFR3 (FLT4) and the fully processed, mature forms also to KDR. FLT4 is primarily expressed on cells of the

\footnotetext{
* Correspondence: jrh@dsmz.de

'Department of Human and Animal Cell Cultures, German Collection of

Microorganisms and Cell Cultures, Braunschweig, Germany

Full list of author information is available at the end of the article
}

lymphatic endothelium [1]. VEGFs and VEGF-Rs are important for vessel formation in healthy individuals, but also for tumor angiogenesis [2]. Moreover, the VEGF-Rs are not only expressed on endothelia, but also on different types of solid tumor cells and on leukemic cells [3-11]. The interaction of receptors with their ligands mediates survival and can lead to proliferation of the malignant cells $[2,12]$.

Even twenty years after their discovery, little is known about the regulation of the three VEGF-Rs. On the transcriptional level, NF- $\kappa \mathrm{B}$ and the NF- $\kappa \mathrm{B}$ target Prox 1 have been described as activators of FLT4 in lymphatic endothelial cells [13]. Epigenetic mechanisms contribute

\section{() Biomed Central}


to the regulation of FLT1 and KDR but this is not investigated in great detail $[14,15]$.

We set out to test whether DNA methylation is also responsible for the silencing of FLT4. We determined the methylation status of KDR and FLT4 in human umbilical vein endothelial cells (HUVECs), dermal microvascular endothelial cells (HDMECs) and in a large panel of leukemia and lymphoma cell lines. Confirming that expression of KDR and FLT4 is epigenetically regulated, we observed an inverse correlation between promoter methylation and receptor expression. Furthermore, the demethylating agent 5-Aza-2'deoxycytidine (5-Aza-dC) induced expression of KDR and FLT4 in methylated, but not in unmethylated cell lines.

\section{Methods}

\section{Cell lines and primary cell cultures}

The cell lines in this study were taken from the stock of the cell bank (DSMZ-German Collection of Microorganisms and Cell Cultures; http://www.dsmz.de). Detailed references and cultivation protocols have been described previously [16]. Primary HDMECs were purchased from Clonetics/Lonza (Verviers, Belgium). Primary HUVECS (pooled) were purchased from PromoCell (Heidelberg, Germany). HDMECs and HUVECs were cultured in endothelial cell growth medium MV (Promo Cell).

\section{CpG island search}

CpG island search was done with Methyl Primer Express v1.0 software and EMBOSS CpG plot (http://www.ebi.ac. uk/Tools/emboss/cpgplot/index.html). The criteria for an island were: GC content > 50\%; CpG observed versus CpG expected ratio $>0.6$, length $>100 \mathrm{bp}$.

\section{Methylation-specific polymerase chain reaction (MSP)}

Bisulfite conversion of DNA was performed as described by the supplier (EpitTect Bisulfite Kit, Qiagen, Hilden, Germany). For detecting FLT4 and KDR promoter methylation, we performed nested PCR with first round primers (FLT4 BSP fwd 5'-AAA TAT TTG GGG GAG TTT TAA A-3', FLT4 BSP rev 5'-CCC AAT CTC AAA AAT AAA CAA A-3'; KDR BSP fwd 5'-AAG TTG TTG TTT TGG GAT GTT T-3', KDR BSP rev 5'-AAA TAA ACT CCT TAC CCA CAA A-3') amplifying converted DNA independently of the methylation status (bisulfitespecific PCR or BSP; annealing temp.: $54.9^{\circ} \mathrm{C}$ for FLT4 BSP, $54 . \overline{7}^{\circ} \mathrm{C}$ for $K D R$ BSP, 35 cycles), and second round primers for $\mathrm{M}$ - and U-PCR specifically recognizing the methylated or unmethylated versions of the promoter (FLT4 $M$ fwd 5'-GTC GGT TAT TTC GGG TGT TTC -3', FLT4 M rev 5'-AAT ATC GAC GAA CAA TAT CGA CG-3', FLT4 U fwd 5'-GGG TTG GTT ATT TTG GGT GTT TT-3', FLT4 U rev 5'-ACA CAA TAT CAA
CAA ACA ATA TCA ACA-3', KDR M fwd 5'-CGT TTT CGC GTT TTA GAG TTT C-3', KDR M rev 5'GCG CAA ATA ATA CCC GAC G-3', KDR U fwd 5'TTT TGT TTT TGT GTT TTA GAG TTT T-3', KDR U rev 5'-ACA CAC AAA TAA TAC CCA ACA-3'). PCR products of the initial BSP were diluted 1:100 to 1:4.000 for subsequent M- and U-PCR. Annealing temperature was $61.2^{\circ} \mathrm{C}$ for $F L T 4 \mathrm{M}$ - and U-PCR, $58^{\circ} \mathrm{C}$ for KDR M- and U-PCR with 30 cycles each. Epitect PCR Control DNA (Qiagen) was used as control for methylated and unmethylated templates.

\section{Bisulfite sequencing}

To confirm the methylation status of the FLT4 and KDR promoters, genomic DNA was bisulfite converted according to the manufacturer's instructions (Qiagen). Subsequently, amplification of the promoter regions (FLT4: 337 bp; KDR: 612 bp) was performed using BSP primers, specifically binding bisulfite converted DNA (for primer sequence and PCR conditions see MSP section). Resulting PCR products were purified, cloned into the pGEM-TEasy vector (Promega, Madison, WI, USA) and sequenced. Sequences were evaluated using BiQ Analyzer (http://biq-analyzer.bioinf.mpi-sb.mpg.de) and had to conform to at least $90 \%$ bisulfite conversion rate. In addition, identical clones were excluded from the analysis.

\section{Gene expression analyses}

Quantitative PCR was performed on a 7500 Applied Biosystems (Darmstadt, Germany) real-time PCR system using the manufacturer's protocol. RNA was prepared using the RNeasy Mini kit (Qiagen). This kit includes a DNase digestion step to avoid false positives resulting from contaminating genomic DNA. For mRNA quantification, reverse transcription was performed using the SuperScript II reverse transcriptase kit (Invitrogen, Karlsruhe, Germany). TaqMan probes (Applied Biosystems) were used to quantify human FLT4 (Hs 01047677 $\mathrm{m} 1$ ) and $K D R$ (Hs $00911700 \mathrm{~m} 1)$ expression levels with TATA box binding protein (TBP) as endogenous control. For interferon gamma inducible protein 10 (IP-10) and tumor necrosis factor alpha (TNF $)$ ), SYTO-82 (Molecular Probes, Leiden, Netherlands) was used as fluorescent dye, ImmoMix (Biline, Luckenwalde, Germany) as PCR master mix, and ribosomal protein $S 9$ (RPS9) as endogenous control. The following primers were used: $T N F \alpha$ exon 2 fwd 5'-CCC CAG GGA CCT CTC TCT AA-3', TNF $\alpha$ exon 3 rev 5'-TGG GCT ACA GGC TTG TCA CT-3'; IP-10 exon 1 fwd 5'-GCC ATT CTG ATT TGC TGC CTT A -3', IP-10 exon 2 rev 5'-TGA TGC AGG TAC AGC GTA CAG-3'; RPS9 exon 2 fwd 5'-GGG AAG CGG AGC CAA CAT G-3', RPS9 exon 3 rev 5'GTT TGT TCC GGA GCC CAT ACT-3'. Relative 
expression levels were calculated using the $\Delta \Delta \mathrm{Ct}$ method.

\section{$\left[{ }^{3} \mathrm{H}\right]$-Thymidine uptake}

Assays of $\left[{ }^{3} \mathrm{H}\right]$-thymidine incorporation were executed as follows: $1.25 \times 10^{4}$ cells (in $100 \mu \mathrm{l}$ ) were seeded in triplicate in 96-well flat-bottom microtiter cell culture plates. Inhibitors were added as $2 \mathrm{x}$ concentrated solution in a $100 \mu \mathrm{l}$ volume. For the last $3 \mathrm{~h}$ of the incubation period, $1 \mu \mathrm{Ci}\left[{ }^{3} \mathrm{H}\right]$-thymidine (Hartmann Analytic, Braunschweig, Germany) was added to each well.

\section{Western blot analysis, antibodies, reagents}

Samples were prepared as described previously [17]. Anti FLT4, ERK and pERK antibodies were purchased from Santa Cruz (Heidelberg, Germany). Anti $\mathrm{I} \kappa \mathrm{B}, \mathrm{pI} \kappa \mathrm{B}, \mathrm{KDR}$, p38 MAPK and pp38 MAPK antisera were obtained from Cell Signalling (New England Biolabs, Frankfurt, Germany). The anti GAPDH monoclonal antibody (mAb) was purchased from Abcam (Cambridge, UK). Specific bands on nitrocellulose membranes were visualized with the biotin/streptavidin-horseradish peroxidase system (Amersham, Freiburg, Germany) in combination with the "Renaissance Western Blot Chemoluminescence Reagent" protocol (Perkin Elmer, Waltham, MA, USA). Synthetic macrophage activating factor of $2 \mathrm{kDa}$ molecular mass (MALP-2) was a gift from P. Mühlradt to $H$. Weich. The preparation was free of endotoxin.

\section{Analysis of FLT4 and KDR protein expression by flow cytometry}

For detection of CD31 (Becton Dickinson Biosciences, Heidelberg, Germany), FLT4 (R\&D Systems, Wiesbaden, Germany), KDR (Reliatech, Wolfenbüttel, Germany) and podoplanin (Reliatech) on the cell surface, cells were washed and incubated with the mouse mAb or with the isotope-matched control mouse immunoglobulin (BD Biosciences) for $30 \mathrm{~min}$ at $4^{\circ} \mathrm{C}$. Subsequently, cells were treated with FITC conjugated anti-mouse secondary Ab (Biozol, Eching, Germany) and propidium iodide. Labeled cells were analyzed on a FACSCalibur (BD Biosciences) using CellQuest Pro software.

\section{Treatment with DNA demethylating agent 5-Aza-2'- deoxycytidine (5-Aza-dC)}

5-Aza-dC (Sigma Aldrich, Taufkirchen, Germany) dissolved in DMSO was used to verify the effect of methylation on expression of FLT4 and KDR. Cells were seeded at a cell density of $5 \times 10^{5}$ cells/ml, 5 -Aza-dC was added at a final concentration of $5 \mu \mathrm{M}$. Control cells were treated with $0.05 \%$ DMSO. After $2 \mathrm{~d}$, half of the medium was replenished with medium with/without 5 -Aza-dC $(5 \mu \mathrm{M})$. After $3 \mathrm{~d}$, cells were harvested to prepare RNA and protein.

\section{Results and Discussion}

\section{Expression of KDR and FLT4 in leukemia and lymphoma} cell lines

The VEGF-Rs KDR (VEGF-R2) and FLT4 (VEGF-R3) are not only expressed on blood endothelial and lymphendothelial cells, but also on solid tumors and leukemias. Leukemia-derived VEGFs may induce the growth of leukemic cells in an autocrine or paracrine fashion $[7,10,18,19]$. The promoters of VEGF-Rs and their ligands contain $\mathrm{CpG}$ islands, regulatory regions that are typically methylated in epigenetically silenced genes [14]. Recent reports show that expression of FLT1 and $K D R$ are controlled by promoter methylation $[14,15]$. However, only a limited number of leukemia and lymphoma cell lines have been tested for VEGF-R expression and promoter methylation hitherto.

To find model systems for $V E G F-R$ regulation, we tested some ninety leukemia and lymphoma cell lines for KDR and FLT4 mRNA expression. Both genes were regularly expressed in leukemia but not in lymphoma cell lines: 10/62 (16\%) cell lines from various leukemic entities expressed KDR, 27/65 (42\%) expressed FLT4 (Table 1). In contrast, $0 / 30$ lymphoma cell lines expressed $K D R$, and only $1 / 30$ (3\%) expressed FLT4 (Table 1). Cell lines with high VEGF-R transcript levels expressed also the corresponding proteins: cell lines CMK, HEL and MEG-01 expressed KDR, whereas cell lines HEL, MHH-CALL2, OCI-AML1 and SUP-B15 were FLT4 positive (Figure 1, Table 2).

\section{OCI-AML1: a model system for VEGF-C induced cell signaling}

Cytokine-dependent cell lines have often and successfully been used as model systems for signal transduction studies. In contrast to primary cells, no contaminating cell fraction effects "false" signals in cell lines, and in contrast to cytokine-independently growing cell lines, cytokine starvation silences the relevant enzymes in cytokinedependent cell lines. We chose cell line OCI-AML1 as this was the only cytokine dependent, FLT4 positive cell line tested (Table 2). The cytokine response profile of this cell line has been published previously [20]. Cell line OCI-AML1 did not show a proliferative response on VEGF-C (data not shown). However, short-term (5 min) stimulation with VEGF-C induced phosphorylation of ERK1/2 (Figure 2). Preincubation with the FLT4 inhibitor MAZ51 inhibited this effect, confirming the specificity of the VEGF-C induced EKR1/2 activation (Figure 2). ERK1/2 phosphorylation was tested because the p42/44 MAPK pathway is a known FLT4 target [21,22]. The results of cell signaling experiments shown in Figure 2 confirm that cell line OCI-AML1 is a model system for FLT4 signaling, expecially as KDR, the second receptor for VEGF-C is not expressed in this cell line (Table 2). 
Table 1 VEGF-R mRNA expression in leukemia and lymphoma cell lines

\begin{tabular}{|c|c|c|c|c|c|c|}
\hline \multicolumn{7}{|c|}{ KDR } \\
\hline & +++ & ++ & + & $(+)$ & - & $\Sigma$ \\
\hline AML & 0 & 2 & 0 & 3 & 16 & 21 \\
\hline pre-B ALL & 0 & 0 & 0 & 1 & 10 & 11 \\
\hline T-ALL & 0 & 0 & 0 & 2 & 9 & 11 \\
\hline NK & 0 & 0 & 0 & 0 & 5 & 5 \\
\hline$C M L$ & 1 & 0 & 0 & 1 & 12 & 14 \\
\hline $\mathrm{HL}$ & 0 & 0 & 0 & 0 & 5 & 5 \\
\hline $\mathrm{ALCL}$ & 0 & 0 & 0 & 0 & 5 & 5 \\
\hline$B L$ & 0 & 0 & 0 & 0 & 5 & 5 \\
\hline DLBCL & 0 & 0 & 0 & 0 & 5 & 5 \\
\hline $\mathrm{FL}$ & 0 & 0 & 0 & 0 & 5 & 5 \\
\hline $\mathrm{MCL}$ & 0 & 0 & 0 & 0 & 5 & 5 \\
\hline \multirow[t]{3}{*}{$\Sigma$} & 1 & 2 & 0 & 7 & 82 & 92 \\
\hline & \multicolumn{5}{|c|}{ FLT4 } & \\
\hline & +++ & ++ & + & $(+)$ & - & $\Sigma$ \\
\hline $\mathrm{AML}$ & 0 & 2 & 4 & 3 & 14 & 23 \\
\hline pre-B ALL & 0 & 3 & 1 & 3 & 4 & 11 \\
\hline T-ALL & 0 & 0 & 2 & 4 & 5 & 11 \\
\hline NK & 0 & 0 & 0 & 0 & 5 & 5 \\
\hline$C M L$ & 0 & 1 & 1 & 3 & 10 & 15 \\
\hline $\mathrm{HL}$ & 0 & 0 & 0 & 1 & 4 & 5 \\
\hline ALCL & 0 & 0 & 0 & 0 & 5 & 5 \\
\hline$B L$ & 0 & 0 & 0 & 0 & 5 & 5 \\
\hline DLBCL & 0 & 0 & 0 & 0 & 5 & 5 \\
\hline $\mathrm{FL}$ & 0 & 0 & 0 & 0 & 5 & 5 \\
\hline $\mathrm{MCL}$ & 0 & 0 & 0 & 0 & 5 & 5 \\
\hline$\Sigma$ & 0 & 6 & 8 & 14 & 67 & 95 \\
\hline
\end{tabular}

$K D R$ and FLT4 mRNA expression levels were determined by quantitative realtime PCR. TBP expression was used as endogenous control and cell lines CMK $(K D R)$ and HEL (FLT4) were used for normalization. Relative quantification: +++ $\geq 5 ;++\geq 1 ;+\geq 0.2 ;(+) \geq 0.04 ;-<0.04$. AML, acute myeloid leukemia; ALL, acute lymphoblastic leukemia; NK, natural killer leukemia; CML, chronic myeloid leukemia; $\mathrm{HL}$, Hodgkin lymphoma; $\mathrm{ALCL}$, anaplastic large cell lymphoma; BL, Burkitt lymphoma; DLBCL, diffuse large B cell lymphoma; $F L$, follicular lymphoma, MCL, mantle cell lymphoma

\section{KDR: promoter methylation and gene expression}

To test whether $K D R$ is epigenetically regulated, we performed bisulfite sequencing of $K D R$ negative and positive cell lines and of primary endothelial cells. The KDR negative cell line DOHH-2 had a highly methylated $K D R$ promoter, the $K D R$ positive cell line HEL was nearly unmethylated (Figure 3). Largely unmethylated were also HDMECs and HUVECs, both expressing KDR (Figure 3). To assess the $K D R$ methylation status for a larger number of cell lines, we performed methylationspecific PCR (MSP), a technique less costly and laborious than bisulfite sequencing. The majority of $K D R$ negative cell lines were methylated, $K D R$ positive HUVECs were unmethylated (Figure 4). However, even HDMECs were U-and M-PCR positive although they expressed high $K D R$ levels and although only a small

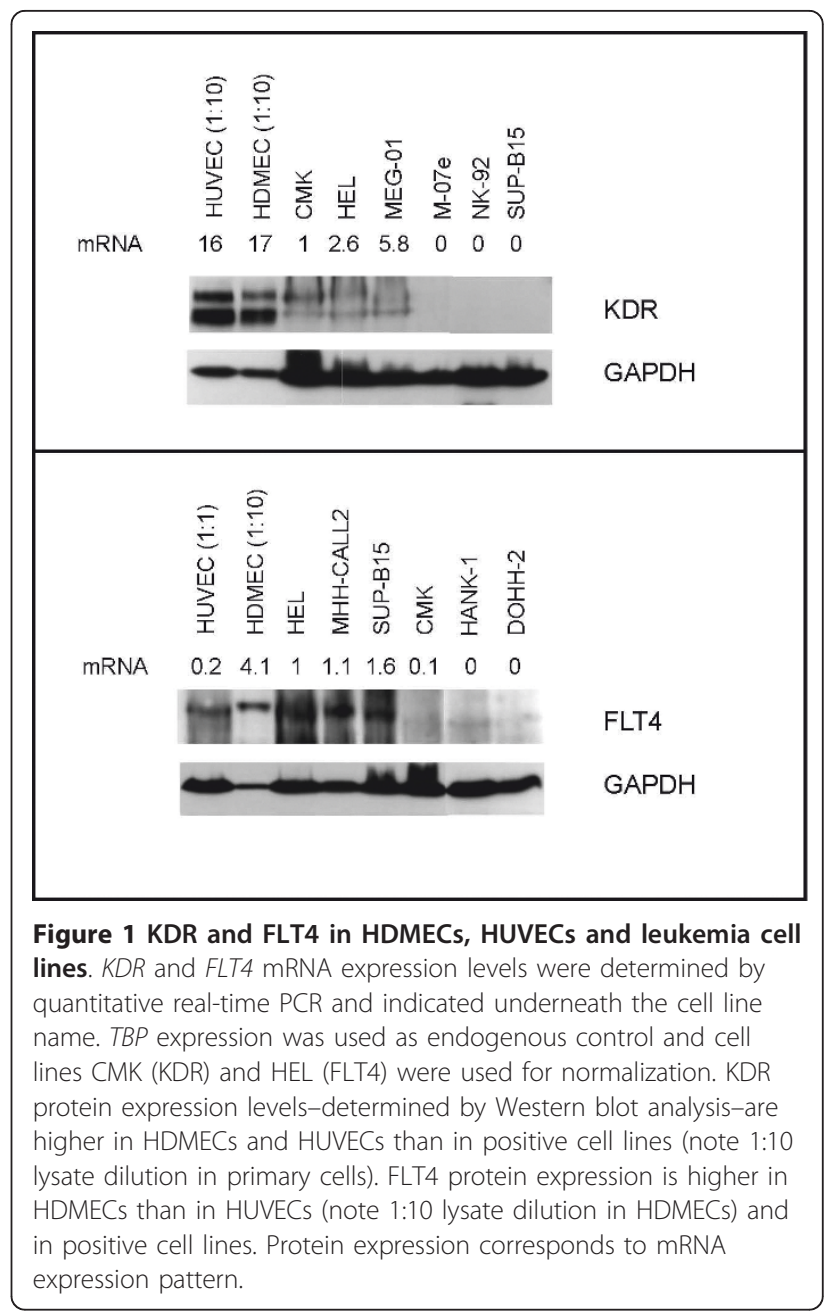

minority of clones were methylated according to sequencing analysis (Figures 3 and 4). Apparently, a low proportion of methylated CpGs was sufficient to yield signals in the M-PCR. The same was true for U-PCR: the KDR negative cell line DOHH-2 - highly methylated according to the results of bisulfite sequencing-showed signals in $\mathrm{M}$ - and in U-PCR (Figure 3, Table 2).

In spite of the high sensitivity-a certain drawback of the PCR-based MSP technique-the accuracy of KDR MPCR was $88 \%$ supporting the notion that $K D R$ expression is regulated by DNA methylation (Table 2).

\section{FLT4: promoter methylation and gene expression}

Bisulfite sequencing and BSP analysis were also performed to analyze the methylation status of FLT4 in cell lines, HUVECs and HDMECs. Results of bisulfite sequencing showed that FLT4 was largely methylated in the FLT4 negative cell line EM-2 and unmethylated in the FLT4 positive cell line SUP-B15 as it was in HUVECs and HDMECs (Figure 5). MSP analysis confirmed that FLT4 exhibited the inverse correlation 
Table 2 Promoter methylation status and expression levels of KDR and FLT4

\begin{tabular}{|c|c|c|c|c|c|c|}
\hline & \multicolumn{3}{|c|}{$K D R$} & \multicolumn{3}{|c|}{ FLT4 } \\
\hline & MSP & mRNA & protein & MSP & mRNA & protein \\
\hline 697 & M & 0.08 & neg & $M / U$ & 0 & neg \\
\hline ALL-SIL & $M$ & 0 & neg & U & 0.3 & neg \\
\hline AP-1060 & $M / U$ & 0 & n.d. & $M / U$ & 0 & n.d. \\
\hline BV-173 & M & 0 & neg & U & 1.4 & pos \\
\hline CMK & $M / U$ & 1 & pos & M & 0.1 & neg \\
\hline $\mathrm{DOHH}-2$ & $M / U$ & 0 & neg & $M / U$ & 0 & neg \\
\hline EM-2 & $M / U$ & 0 & neg & M & 0 & neg \\
\hline HANK-1 & M & 0 & neg & M & 0 & neg \\
\hline HEL & U & 2.6 & pos & U & 1 & pos \\
\hline$H L-60$ & M & 0 & neg & M & 0.1 & neg \\
\hline JURL-MK1 & U & 0.15 & n.d. & n.d. & n.d. & n.d. \\
\hline L-82 & M & 0 & n.d. & M & 0 & n.d. \\
\hline LOUCY & n.d. & 0.13 & neg & $M / U$ & 0 & neg \\
\hline M-07e & $M / U$ & 0.03 & neg & U & 0.1 & neg \\
\hline MEG-01 & U & 5.8 & pos & U & 0.2 & pos \\
\hline MEGAL & M & 0 & neg & $M / U$ & 0.3 & neg \\
\hline MHH-CALL2 & $M / U$ & 0 & neg & U & 1.1 & pos \\
\hline MHH-TALL1 & M & 0.08 & n.d. & n.d. & n.d. & n.d. \\
\hline MOLT-4 & M & 0 & n.d. & $M / U$ & 0 & n.d. \\
\hline MUTZ-3 & n.d. & n.d. & n.d. & U & 0.6 & neg \\
\hline MUTZ-8 & n.d. & n.d. & n.d. & $M / U$ & 0.3 & neg \\
\hline NK-92 & M & 0 & neg & $M / U$ & 0 & neg \\
\hline OCI-AML1 & $M / U$ & 0 & neg & $M / U$ & 1.3 & pos \\
\hline SC-1 & M & 0 & n.d. & M & 0 & n.d. \\
\hline SKNO-1 & U & 0.08 & neg & n.d. & n.d. & n.d. \\
\hline SUP-B15 & M & 0 & neg & $U$ & 1.6 & pos \\
\hline TF-1 & U & 0.1 & pos & U & 0 & neg \\
\hline THP-1 & $M / U$ & 0 & n.d. & $M / U$ & 0 & n.d. \\
\hline
\end{tabular}

KDR and FLT4 methylation was determined by MSP. M, positive in M-PCR; $U$, positive in U-PCR, M/U positive in $\mathrm{M}$ - and in U-PCR; n.d., not done. VEGF-R mRNA expression levels were determined by quantitative real-time PCR. Cell lines CMK (KDR) and HEL (FLT4) were used for normalization (set to 1). Protein expression was done by Western blot analysis. The accuracy of KDR M-PCR (mRNA positivity > 0.1 ) is $88 \%$, the accuracy of FLT4 M-PCR (mRNA positivity > $0.1)$ is $80 \%$

between promoter methylation and gene expression that is indicative for epigenetic regulation (Figure 4, Table 2). However, the accuracy of FLT4 M-PCR (80\%) was lower than for KDR M-PCR (88\%). Of note was also that TF-1 cells did not express FLT4 although the promoter was unmethylated (Table 2). These data suggested that regulatory mechanisms other than DNA methylation are also important for the regulation of FLT4.

\section{Effect of DNA demethylating agent 5-Aza-dC on expression of KDR and FLT4}

To test whether KDR and FLT4 were silenced by promoter methylation, we treated methylated and unmethylated cell lines with the DNA demethylating agent 5Aza-dC. In 4/5 KDR-negative cell lines, expression of

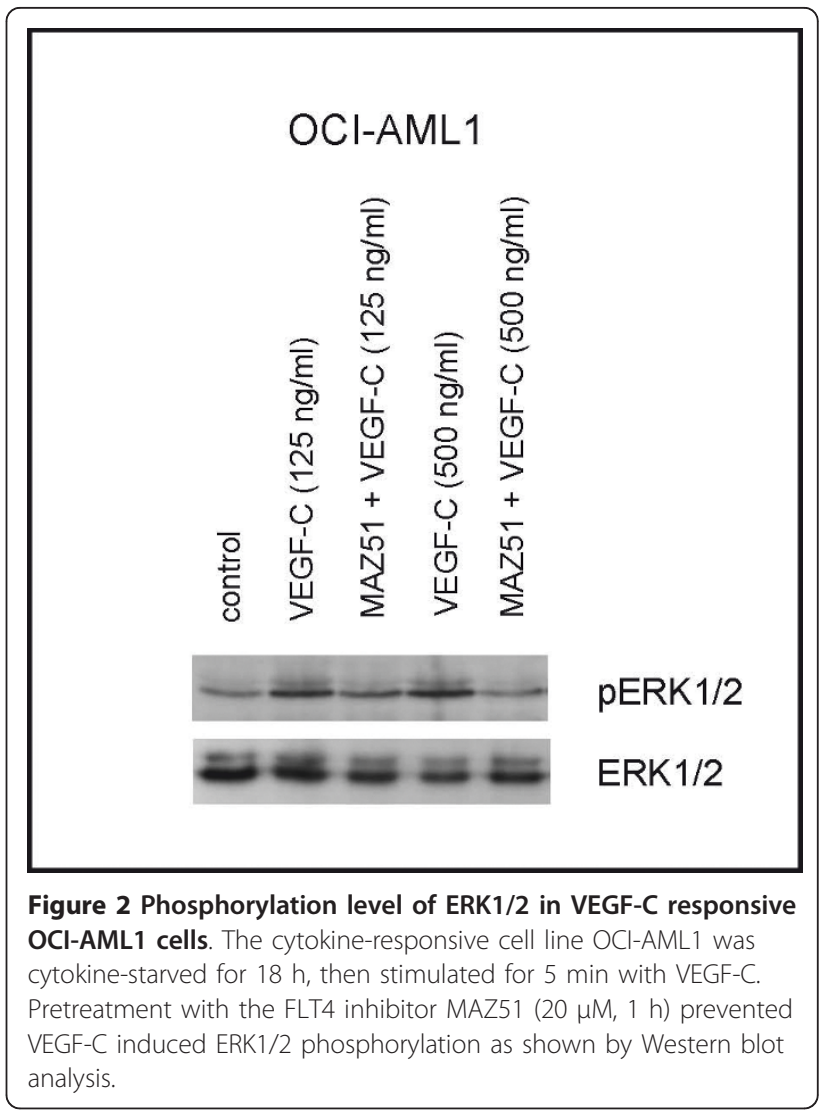

$K D R$ was induced by DNA demethylation (Table 3 ). FLT4 expression was upregulated in $4 / 4$ negative cell lines (Table 3). KDR and FLT4 expression in positive cell lines were not affected (Table 3 ). Although these results confirmed that promoter methylation plays a role for the regulation of these VEGF-Rs, we also noted substantial differences in the levels of 5-Aza-dC-triggered gene induction between different cell lines (Table $3)$. Furthermore, even in the most sensitive cell lines (HL-60 for KDR induction, EM-2 for FLT4 induction), demethylation did not induce mRNA expression that would translate into protein levels detectable by Western blot analysis (data not shown). These results suggest that other mechanisms than DNA methylation are also involved in the regulation of KDR and FLT4.

Besides DNA methylation, also histone modifications are epigenetic mechanisms that affect the expression of individual genes. Just to mention two examples, acetylated histone $\mathrm{H} 3$ (at lysine 9 and 14) is a marker for gene activation [23], tri-methylation of histone H3 lysine 27 stands for gene suppression [24]. Furthermore, epigenetic modifications can influence each other: methylated CpGs in a promoter region can be targeted by proteins that interact with histone deacetylases. The consequence is an inactive chromatin status and transcriptional repression $[25,26]$. 


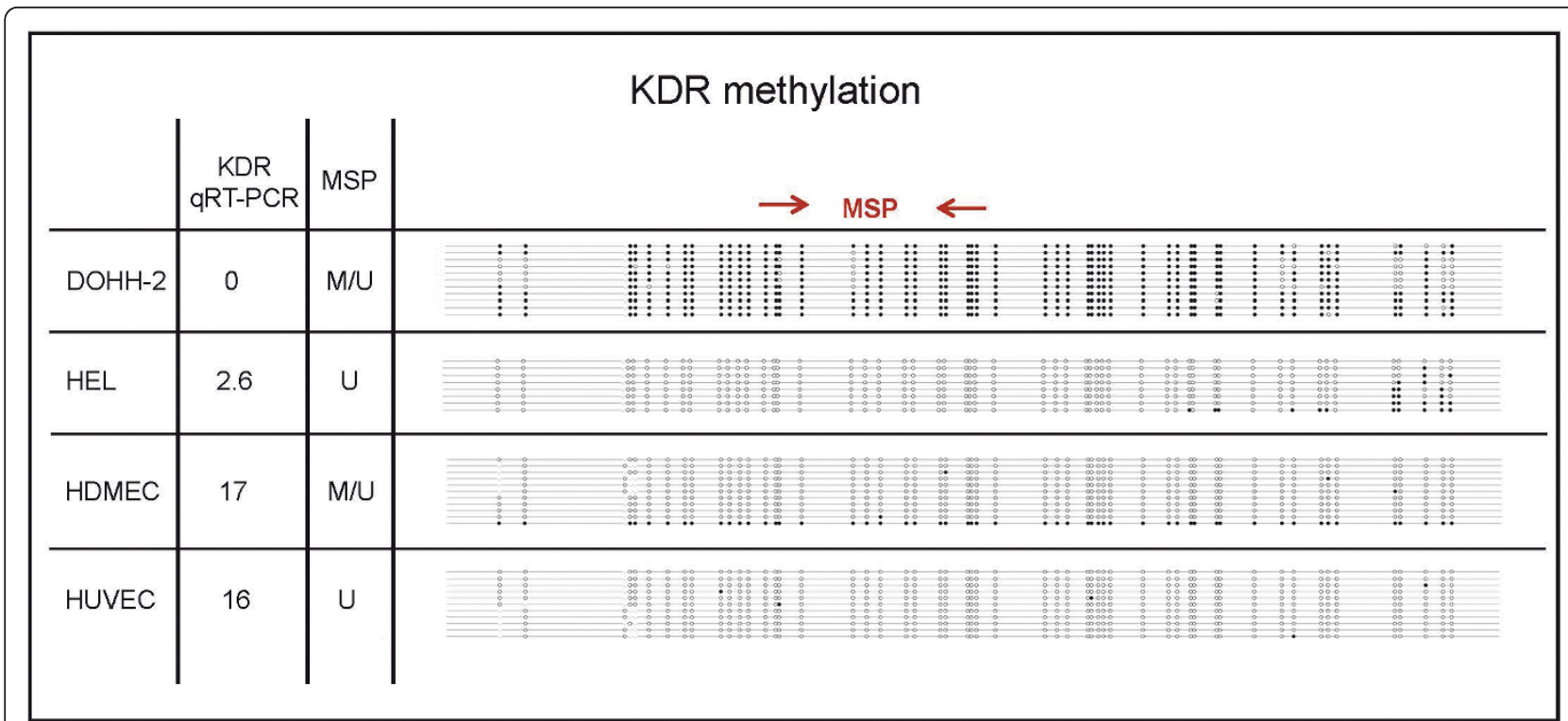

Figure 3 Bisulfite sequencing of the KDR promoter. A CpG island is located between -1231 and 1125 relative to the ATG codon of KDR. The 3' part of the KDR promoter region and exon 1 ( $612 \mathrm{bp}, 53 \mathrm{CpG}$ sites) were sequenced after bisulfite conversion of DNA from cell lines DOHH-2 (KDR negative) and HEL (KDR positive) as well as from HDMECs and HUVECs. Each line depicts a sequenced clone representing the methylation status of an individual allele. CpGs are represented as open dots (if unmethylated) or filled dots (if methylated). Results of qRT-PCR and methylation specific PCR (MSP) are shown on the left hand side. M: signal in M-PCR; U: signal in U-PCR.

However, besides epigenetic mechanisms, also the presence or absence of trans-acting factors may govern the expression of KDR and FLT4. Thus, it has been shown that transcription factor binding sites (Sp1, AP-2 and $\mathrm{NF} \kappa \mathrm{B}$ ) are essential for the base-line activity of the $K D R$ promoter [27]. Here, we set out to find whether $\mathrm{NF} \kappa \mathrm{B}$ also plays a role for the expression of FLT4.

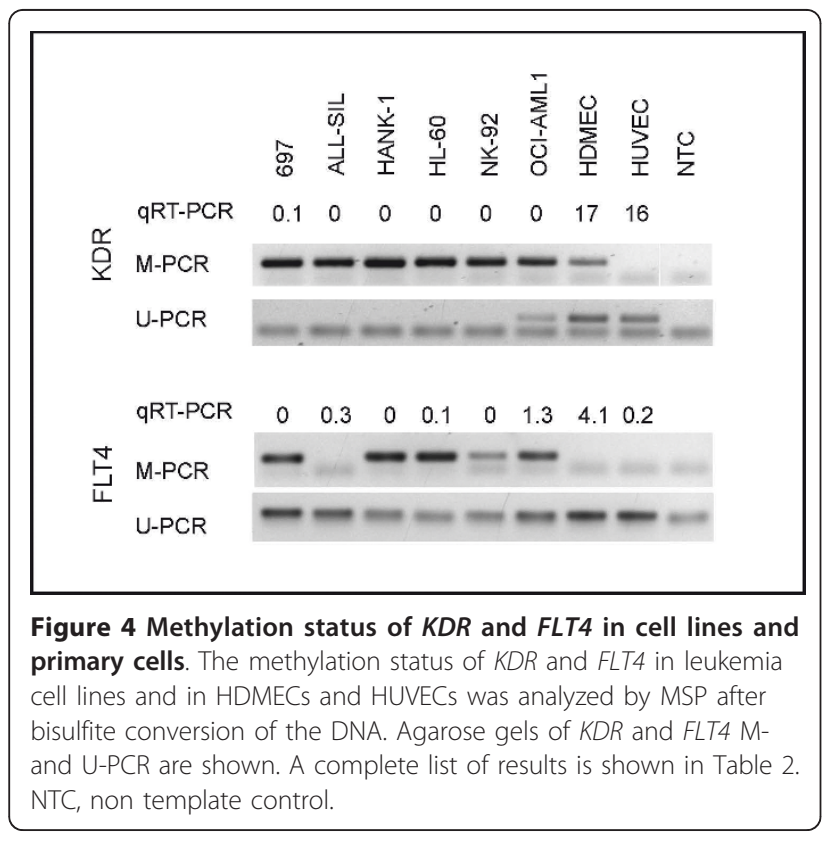

\section{Influence of transactivating factors}

During inflammation, new lymphatic vessels are formed. $\mathrm{NF}-\kappa \mathrm{B}$ is a key mediator of inflammatory processes and has recently been identified as inducer of FLT4 on lymphatic endothelial cells [13]. To test whether NF- $\kappa \mathrm{B}$ contributes to FLT4 expression in leukemic cells, we stimulated the FLT4 negative cell line EM-2 and the FLT4 positive cell line OCI-AML1 with synthetic MALP-2. MALP-2 binds to toll-like receptors-2 and -6 [28]. MALP-2 triggers the NF- $\kappa$ B pathway [29] which leads to the expression of NF- $\kappa \mathrm{B}$ targets like TNF $\alpha$ [30].

Accordingly, MALP-2 (100 ng/ml, $7 \mathrm{~min})$ induced phosphorylation and degradation of the NF- $\kappa$ B inhibitor $\mathrm{I} \kappa \mathrm{B}$ and stimulated phosphorylation of p38 in cell lines EM-2 and OCI-AML1 (Figure 6). MALP-2 (100 ng/ml, $1 \mathrm{~h})$ triggered expression of the NK $-\kappa \mathrm{B}$ targets $T N F \alpha$ $(80 \times$ in EM-2, 1000x in OCI-AML1) and $I P-10(600 \times$ in EM-2, > 1000 $\times$ in OCI-AML1) in both cell lines. However, the expression of FLT4 was not affected, neither in the FLT4 positive cell line OCI-AML1 nor in the FLT4 negative (methylated) cell line EM-2. MALP-2 did also not increase the FLT4 stimulating effect of 5-Aza-dC on EM-2 cells (data not shown). Thus, our results do not support the view that NF- $\kappa \mathrm{B}$ is a transactivator of FLT4. We observed a 10 -fold increase in $K D R$ in cell lines OCI-AML1 and EM-2 (the latter pretreated with 5-Aza$\mathrm{dC}$ ). However, as the level reached after stimulation was still extremely low, it appears unlikey that NF- $\kappa \mathrm{B}$ is an important regulator for $K D R$ either. 


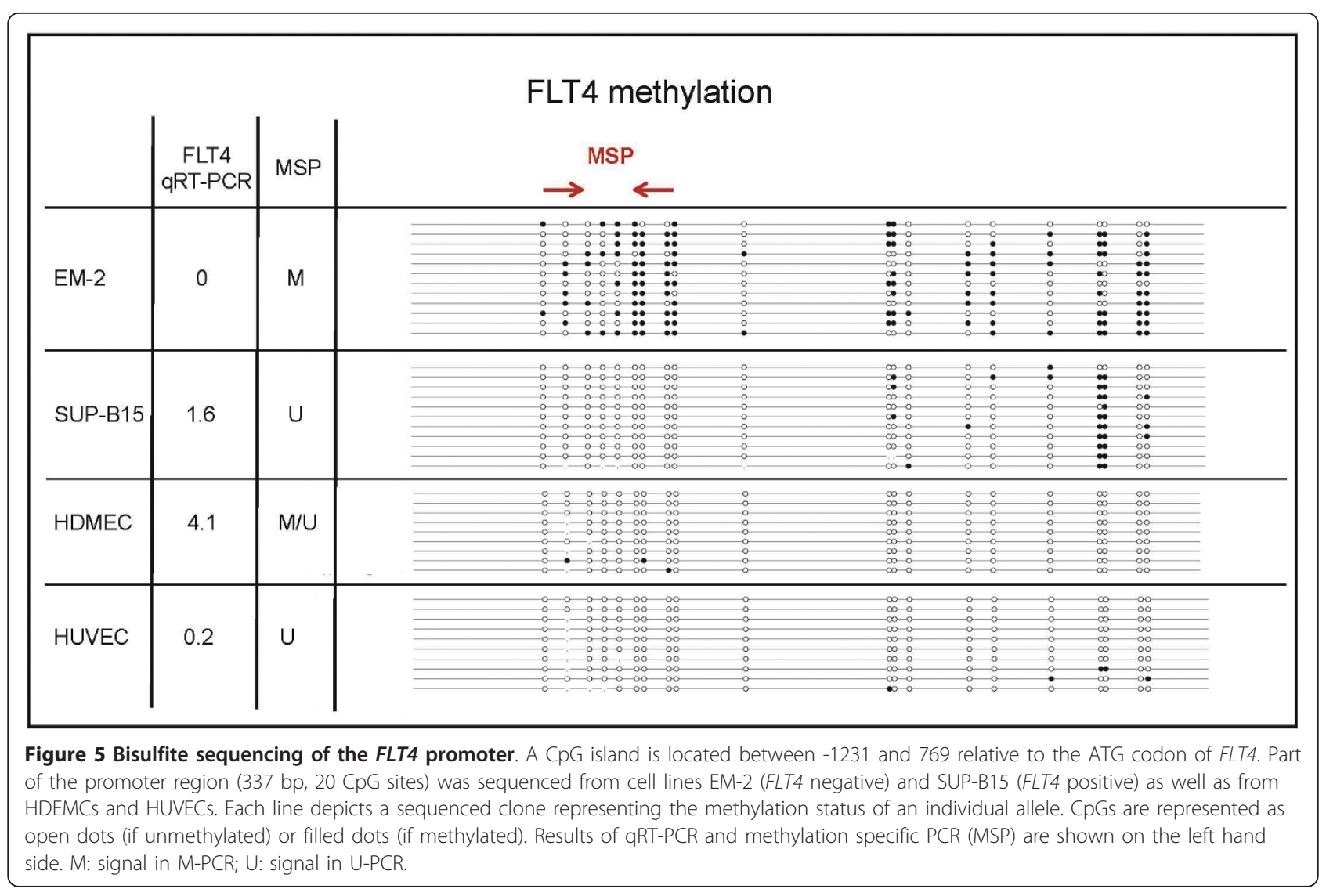

\section{KDR and FLT4 in HDMECs and HUVECs}

HDMECs, HUVECs and KDR positive leukemia cell lines exhibited demethylated $K D R$ promoters (Figure 3, Table 2). However, mRNA and protein levels were distinctly higher in the primary cells than in the leukemia cell lines (Figure 1). Results of Western blot analysis were confirmed by flow cytometry (Figure 7). HDMECs and HUVECs expressed the pan-endothelial marker CD31 (Figure 7). HDMECs, primarily consisting of lymphatic endothelial cells, were also positive for the

Table 3 Effect of 5-Aza-dC on expression of KDR and FLT4

\begin{tabular}{|c|c|c|c|c|}
\hline & \multicolumn{2}{|r|}{$K D R$} & \multicolumn{2}{|r|}{ FLT4 } \\
\hline & mRNA & induced by Aza & mRNA & induced by Aza \\
\hline CMK & pos & - & pos & - \\
\hline $\mathrm{DOHH}-2$ & neg & + & neg & ++ \\
\hline EM-2 & neg & $(+)$ & neg & +++ \\
\hline HL-60 & neg & +++ & pos & - \\
\hline L-82 & neg & - & neg & + \\
\hline$S C-1$ & neg & ++ & neg & + \\
\hline
\end{tabular}

Induction of KDR and FLT4 by 5-Aza-dC ( $5 \mu \mathrm{M}, 3 \mathrm{~d})$ when compared to untreated control cells: $-<2.5$-fold; $(+)>2.5$-fold; $+>10$-fold; $++>40$-fold; + $++>160$-fold. Expression levels were determined by qRT-PCR. TBP expression was used as endogenous control, DMSO $(0.05 \%)$ treated cells were used for normalization

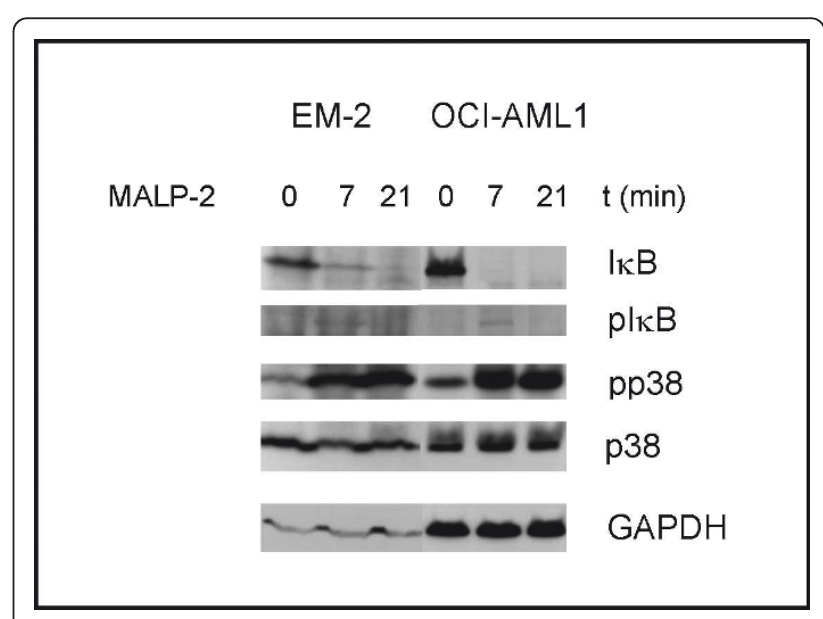

Figure 6 Degradation of $\mathrm{I} \kappa \mathrm{B}$ and phosphorylation of p38MAPK in MALP-2 responsive cell lines. Cell lines EM-2 (FLT4 negative) and OCI-AML1 (FLT4 positive) were stimulated with MALP-2 (100 $\mathrm{ng} / \mathrm{ml})$. The NF- $\kappa$ B inhibitor $\mid \kappa B$ was phosphorylated (7 min) and degraded (7 min, $21 \mathrm{~min}$ ) in both cell lines. Likewise, rapid phosphorylation of p38 MAPK was observed in both cell lines by Western blot analysis. GAPDH is shown as loading control. 
lymphatic vessel marker podoplanin, HUVECs were podoplanin negative (Figure 7). Both types of primary cells expressed much higher levels of KDR than KDRpositive cell lines (Figure 1). Also FLT4 expression levels varied greatly from one cell type to the other: FLT4 expression of HUVECs was comparable to those of FLT4 positive cell lines, while HDMECs showed much higher FLT4 expression levels (Figures 1 and 7). These results are in line with our data of MSP analyses and 5Aza-dC experiments suggesting that DNA methylation

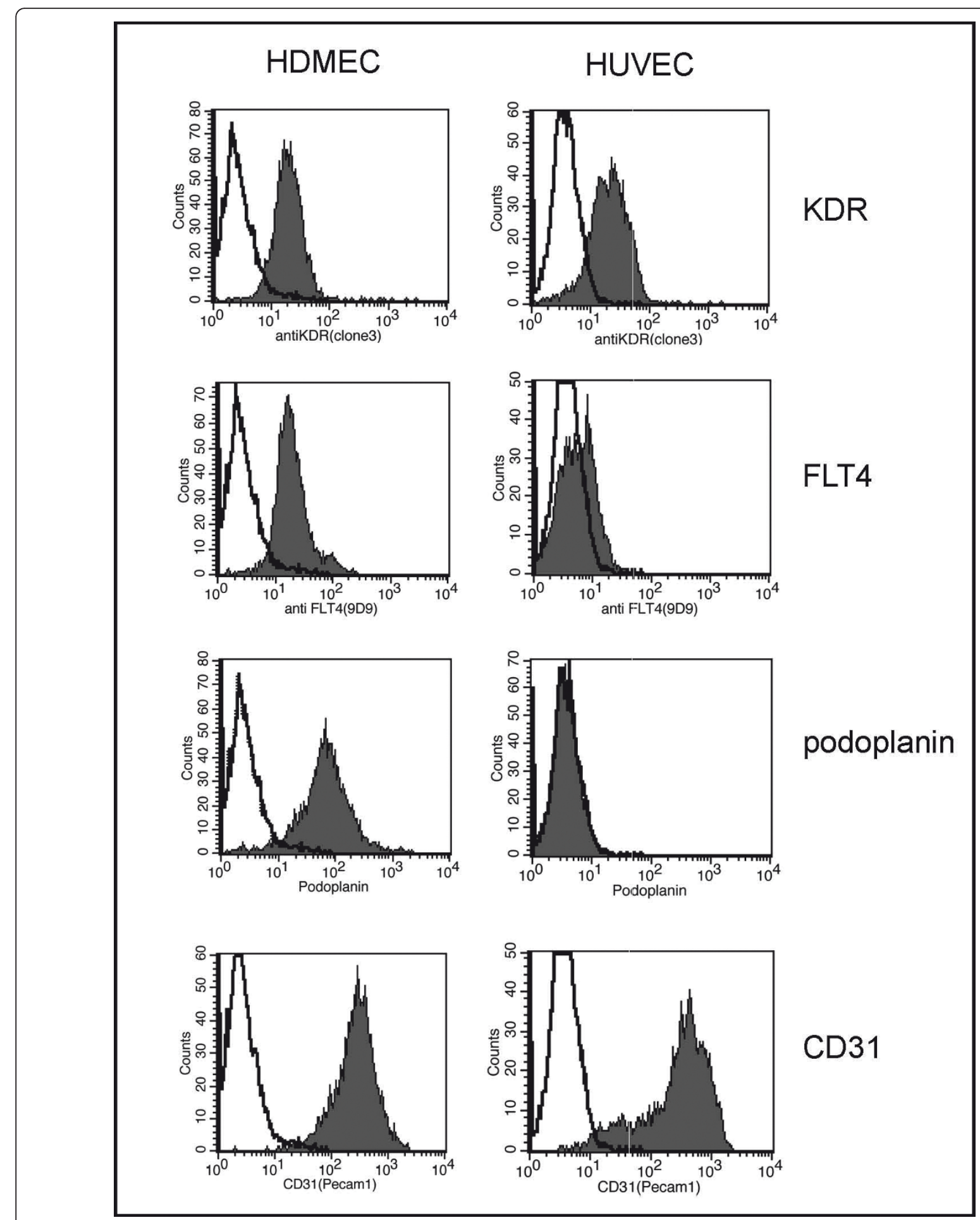

Figure 7 Expression of KDR and FLT4 on HDMECs and HUVECs. Flow cytometry analysis for KDR, FLT4, the lymphatic vessel marker podoplanin and the panendothelial marker CD31. Note that HDMECs and HUVECs show comparable KDR expression levels, while FLT4 is stronger in lymphatic vessel cells (HDMECs) than in blood vessel cells (HUCECs). The non-filled peak shows the corresponding isotype control. 
is not the only mechanism that controls KDR and FLT4 gene expression.

\section{Conclusions}

Our data obtained from primary endothelial cells and from leukemia/lymphoma cell lines show that KDR and FLT4 are epigenetically regulated genes. Both genes can be silenced by methylation. However, if the promoters are unmethylated, other factors are responsible for the extent of KDR and FLT4 expression. Furthermore, we show that the KDR negative/FLT4 positive cell line OCI-AML1 is a model system for FLT4 signal transduction studies.

\section{Acknowledgements}

We thank Rod AF MacLeod (DSMZ) for critically reading the manuscript.

\section{Author details}

${ }^{1}$ Department of Human and Animal Cell Cultures, German Collection of Microorganisms and Cell Cultures, Braunschweig, Germany. ${ }^{2}$ Department of Hematology and Oncology, Georg-August-University Göttingen, University Medical Center, Göttingen, Germany. ${ }^{3}$ Department of Gene Regulation and Differentiation, Helmholtz Centre for Infection Research, Braunschweig, Germany.

\section{Authors' contributions}

$\mathrm{HQ}$ designed the study, performed data analyses and wrote the manuscript. SE carried out bisulfite conversion and helped to design primers for M-PCR and U-PCR. JR performed Western blot analyses. HAW supplied antibodies, HDMECS and HUVECS and gave good advice. MZ performed PCR and FACS analyses. HGD provided cell lines and good advice. All authors read and approved the final manuscript.

\section{Competing interests}

The authors declare that they have no competing interests.

Received: 18 November 2011 Accepted: 17 January 2012

Published: 17 January 2012

\section{References}

1. Larrivée B, Karsan A: Signaling pathways induced by vascular endothelial growth factor (review). Int J Mol Med 2000, 5:447-456.

2. Guo S, Colbert LS, Fuller M, Zhang Y, Gonzalez-Perez RR: Vascular endothelial growth factor receptor-2 in breast cancer. Biochim Biophys Acta 2010, 1806:108-121.

3. de Jong JS, van Diest PV, van der Valk P, Baak JPA: Expression of growth factors, growth inhibiting factors, and their receptors in invasive breast cancer. I: an inventory in search of autocrine and paracrine loops. J Pathol 1998, 184:44-52.

4. Boocock CA, Charnock-Jones DS, Sharkey AM, McLaren J, Barker PJ, Wright KA, Twentyman PR, Smith SK: Expression of vascular endothelial growth factor and its receptors flt and KDR in ovarian carcinoma. J Nat Cancer Inst 1995, 87:506-516.

5. Ferrer FA, Miller $L$, Lindquist R, Kowalczyk P, Laudone VP, Albertsen PC, Kreutzer DL: Expression of vascular endothelial growth factor receptors in human prostate cancer. Urology 1999, 54:567-572.

6. Takahama M, Tsutsumi M, Tsujiuchi T, Kido A, Sakitani H, Iki K, Taniguchi S, Kitamura S, Konishi Y: Expression of vascular endothelial growth factor and its receptors during lung carcinogenesis by $\mathrm{N}$-nitrosobis(2hydroxypropyl)amine in rats. Mol Carcinogenesis 1999, 24:287-293.

7. Dias S, Hattori K, Zhu Z, Heissig B, Choy M, Lane W, Wu Y, Chadburn A, Hyjek E, Gill M, Hicklin DJ, Witte L, Moore MAS, Rafii S: Autocrine stimulation of VEGFR-2 activates human leukemic cell growth and migration. J Clin Invest 2000, 106:511-521.
8. Pazgal I, Boycov O, Shpilberg O, Okon E, Bairey O: Expression of VEGF-C, VEGF-D and their receptor VEGFR-3 in diffuse large B-cell lymphomas. Leuk Lymph 2007, 48:2213-2220.

9. Kivivuori SM, Siitonen S, Porkka K, Vettenranta K, Alitalo R, SaarinenPihkala U: Expression of vascular endothelial growth factor receptor 3 and Tie1 tyrosine kinase receptor on acute leukemia cells. Pediatr Blood Cancer 2007, 48:387-392.

10. Fielder W, Graeven U, Ergün S, Verago S, Kilic N, Stockschläder M, Hossfeld DK: Expression of FLT4 and its ligand VEGF-C in acute myeloid leukemia. Leukemia 1997, 11:1234-1237.

11. Joergensen JM, Soerensen FB, Bendix K, Nielsen JL, Funder A, Karkkainen MJ, Tainola T, Soerensen AB, Pedersen FS, D'Amore F: Expression level, tissue distribution pattern, and prognostic impact of vascular endothelial growth factors VEGF and VEGF-C and their receptors Flt-1, KDR, and Flt-4 in different subtypes of non-Hodgkin lymphomas. Leuk Lymph 2009, 50:1647-1660.

12. Dias S, Choy M, Alitalo K, Rafii S: Vascular endothelial factor (VEGF)-C signaling through FLT-4 (VEGFR-3) mediates leukemic cell proliferation, survival, and resistance to chemotherapy. Blood 2002, 99:2179-2184.

13. Flister MJ, Wilber A, Hall KL, Iwata C, Miyazono K, Nisato RE, Pepper MS, Zawieja DC, Ran S: Inflammation induces lymphangiogenesis through upregulation of VEGFR-3 mediated by NF-KB and Prox1. Blood 2010, 115:418-429.

14. Kim JY, Hwang JH, Zhou W, Shin J, Noh SM, Song IS, Kim JY, Lee SH, Kim J: The expression of VEGF receptor genes is concurrently influenced by epigenetic gene silencing of the genes and VDGF activation. Epigenetics 2009, 4:313-321.

15. Kiec-Wilk B, Razny U, Mathers JC, Dembinska-Kiec A: DNA methylation, induced by beta-carotene and arachidonic acid, plays a regulatory role in the pro-angiogenic VEGF-receptor (KDR) gene expression in endothelial cells. J Physiol Pharmacol 2009, 60:49-53.

16. Drexler HG: Guide to Leukemia-Lymphoma Cell Lines. 2 edition. Braunschweig; 2010.

17. Quentmeier H, Schneider B, Röhrs S, Romani J, Zaborski M, MacLeod RAF, Drexler HG: SET-NUP214 fusion in acute myeloid leukemia- and T-cell acute lymphoblastic leukemia-derived cell lines. J Hematol Oncol 2009, $2: 3$

18. Dias S, Hattori K, Heissig B, Zhu Z, Wu Y, Witte L, Hicklin DJ, Tateno M, Bohlen P, Moore MAS, Rafii S: Inhibition of both paracrine and autocrine VEGF/VEGFR-2 signaling pathways is essential to induce long-term remission of xenotransplanted human leukemias. Proc Natl Acad Sci USA 2001, 98:10857-10862.

19. Bellamy WT, Richter L, Sirjani D, Roxas C, Glinsmann-Gibson B, Frutiger $Y$ Grogan TM, List AF: Vascular endothelial cell growth factor is an autocrine promoter of abnormal localized immature myeloid precursors and leukemia progenitor formation in myelodysplastic syndromes. Blood 2001, 97:1427-1434.

20. Drexler HG, Zaborski M, Quentmeier H: Cytokine response profiles of human myeloid factor-dependent leukemia cell lines. Leukemia 1997 11:701-708.

21. Salameh A, Glavagni F, Bardelli M, Bussolino F, Oliviero S: Direct recruitment of CRK and GRB2 to VEGFR-3 induces proliferation, migration, and survival of endothelial cells through the activation of ERK, AKT, and JNK pathways. Blood 2005, 106:3423-3431.

22. Chien MH, Ku CC, Johansson G, Chen MW, Hsiao M, Su JL, Inoue H, Hua KT, Wei LH, Kuo ML: Vascular endothelial growth factor-C (VEGF-C) promotes angiogenesis by induction of COX-2 in leukemic cells via the VEGF-R3/ JNK/AP-1 pathway. Carcinogenesis 2009, 30:2005-2013.

23. Santos-Rosa H, Caldas C: Chromatin modifier enzymes, the histone code and cancer. Eur J Cancer 2005, 41:2381-2402.

24. Kerppola TK: Polycomb group complexes-many combinations, many functions. Trend Cell Biol 2009, 19:692-704.

25. Herman JG, Baylin SB: Gene silencing in cancer in association with promoter hypermethylation. N Engl J Med 2003, 349:2042-2054.

26. Bird A: DNA methylation patterns and epigenetic memory. Genes Dev 2002, 16:6-21

27. Patterson C, Perrella MA, Hsieh CM, Yoshizumi M, Lee ME, Haber E: Cloning and functional analysis of the promoter for KDR/flk-1, a receptor for vascular endothelial growth factor. J Biol Chem 1995, 39:23111-23118. 
28. Morr M, Takeuchi O, Akira S, Simon MM, Mühlradt PF: Differential recognition of structural details of bacterial lipopeptides by toll-like receptors. Eur J Immunol 2002, 32:3337-3347.

29. Sacht G, Märten A, Deiters U, Süßmuth R, Jung $G$, Wingender E, Mühlradt PF: Activation of nuclear factor-kB in macrophages by mycoplasmal lipopeptides. Eur J Immunol 1998, 28:4207-4212.

30. Kaufmann A, Mühlradt PF, Gemsa D, Sprengler H: Induction of cytokines and chemokines in human monocytes by Mycoplasma fermentansderived lipoprotein MALP-2. Infect Immun 1999, 67:6303-6308.

\section{Pre-publication history}

The pre-publication history for this paper can be accessed here: http://www.biomedcentral.com/1471-2407/12/19/prepub

doi:10.1186/1471-2407-12-19

Cite this article as: Quentmeier et al:: DNA methylation regulates

expression of VEGF-R2 (KDR) and VEGF-R3 (FLT4). BMC Cancer 2012 12:19.

\section{Submit your next manuscript to BioMed Central} and take full advantage of:

- Convenient online submission

- Thorough peer review

- No space constraints or color figure charges

- Immediate publication on acceptance

- Inclusion in PubMed, CAS, Scopus and Google Scholar

- Research which is freely available for redistribution

Submit your manuscript at www.biomedcentral.com/submit 